Supplementary information

To support the manuscript submitted to the Journal of Sulfur Chemistry

\title{
Synergistic promoting effect of ball milling and KF-alumina support as a green tool for
} solvent-free synthesis of 2 -arylidene-benzothiazinones

Ali Sharifi, Mohammad Ansari, Hossein Reza Darabi, M. Saeed Abaee

Department of Organic Chemistry and Natural Products, Chemistry and Chemical Engineering Research Center of Iran, Pajouhesh

Blvd, $17^{\text {th }}$ Km Tehran-Karaj Highway, P.O.Box 14335-186, Tehran, Iran

*Corresponding author. E-mail: sharifi@ccerci.ac.ir 


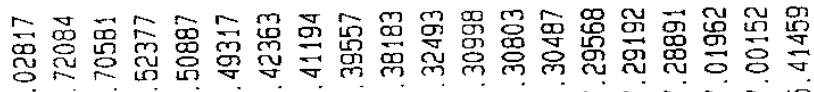

oisisisijisisis

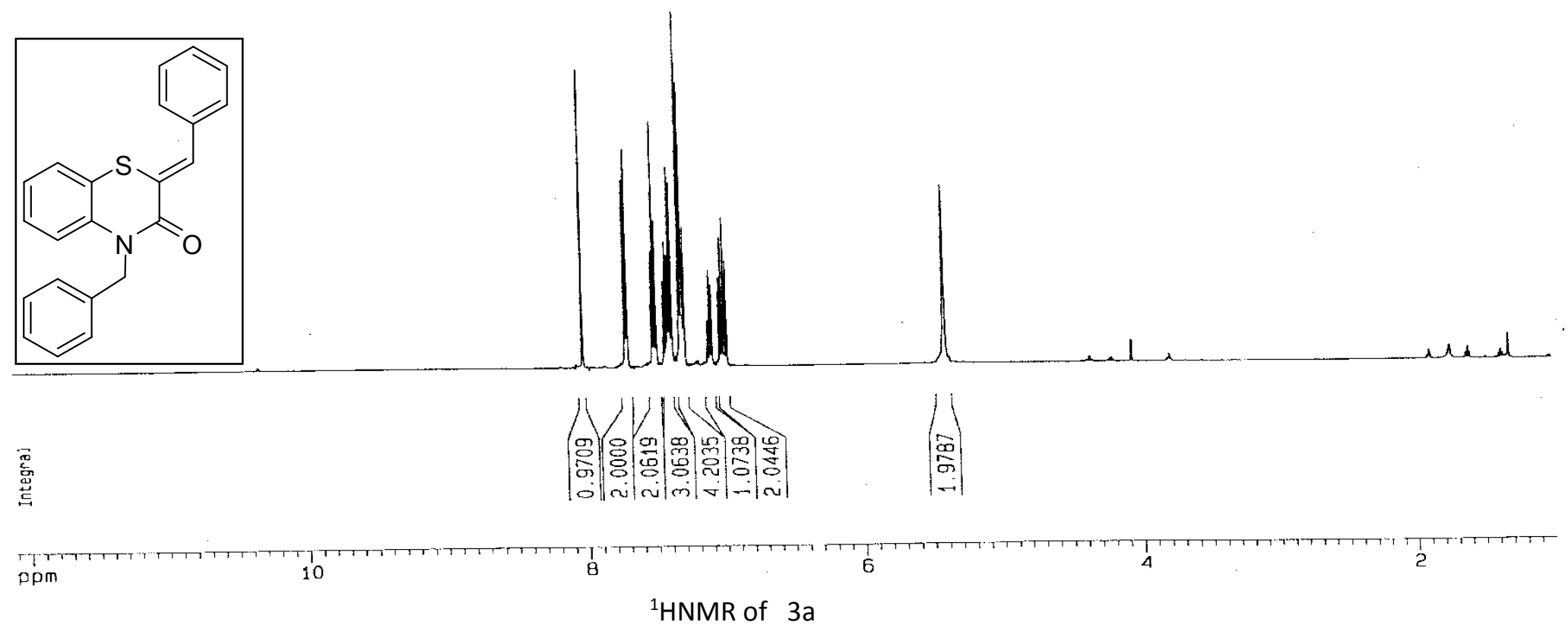



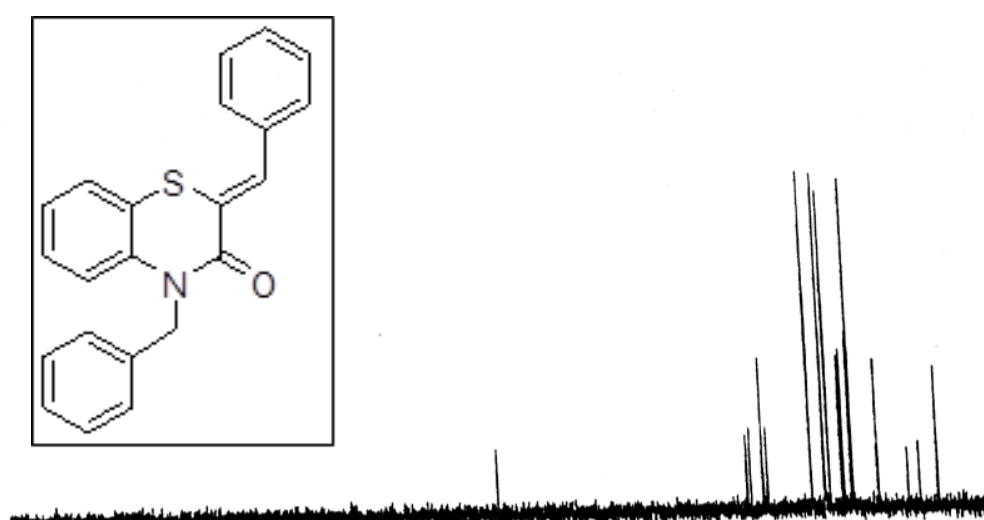

${ }^{13}$ CNMR of $3 a$ 

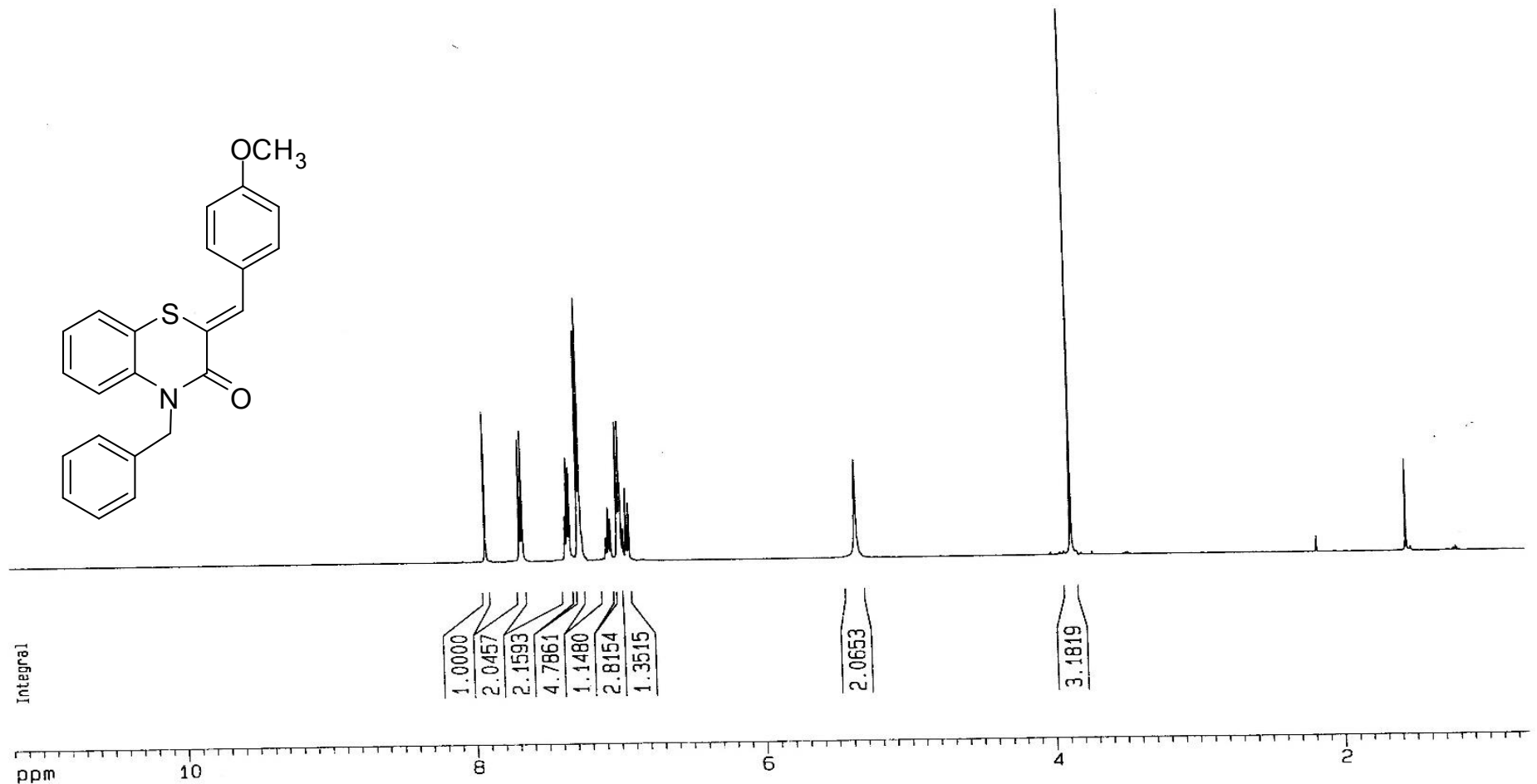

${ }^{1} \mathrm{HNMR}$ of $3 \mathrm{~b}$ 


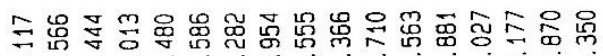

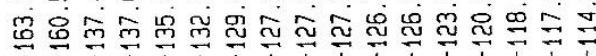

品西芯

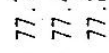

品

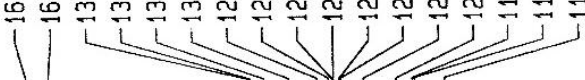

$\forall 1$
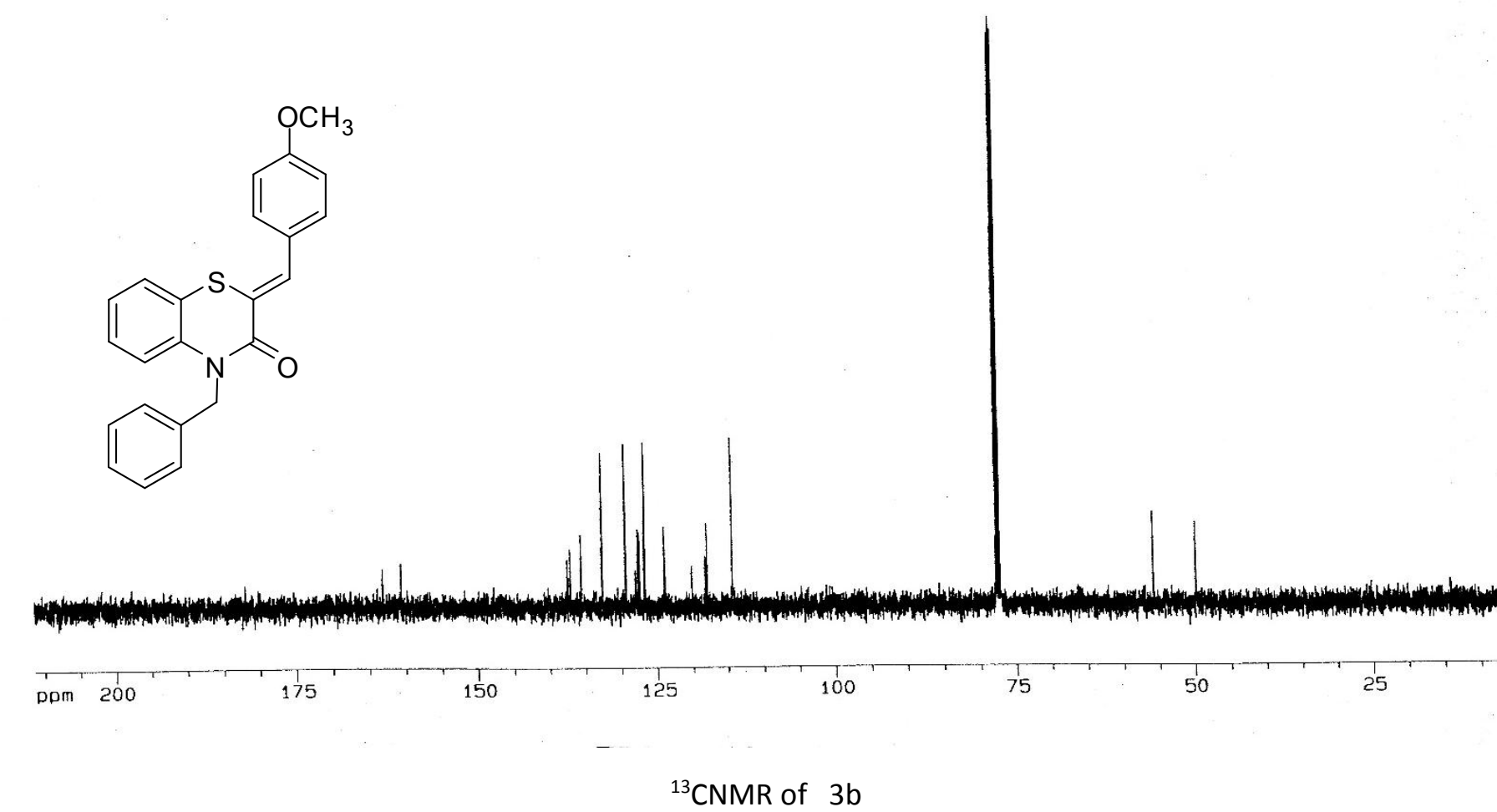

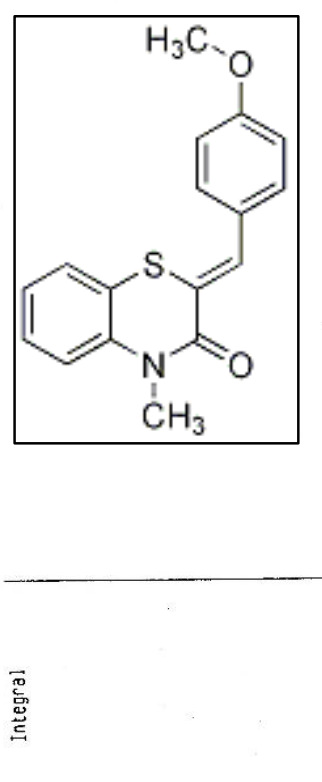

ज़:

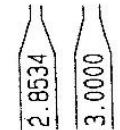
ppm 10 9 8 7 6

${ }^{1}{ }^{1}$

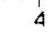

${ }^{1}$ HNMR of $3 e$ 

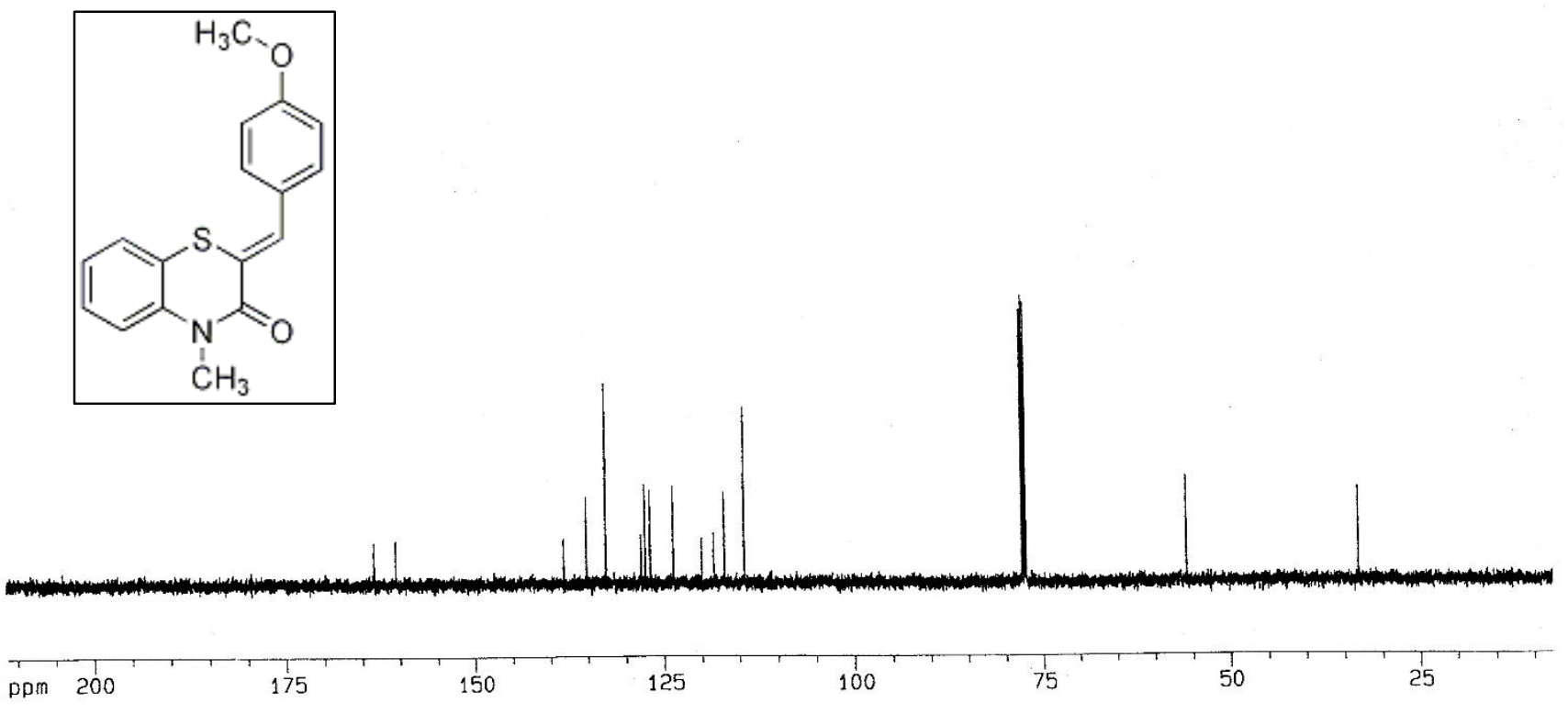

${ }^{13}$ CNMR of $3 e$ 

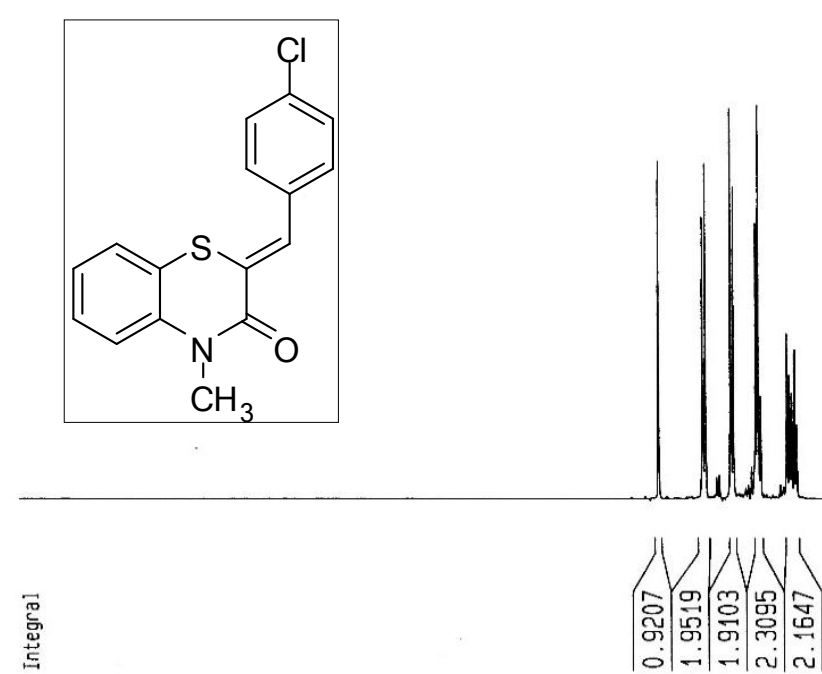$$
\text { . }
$$

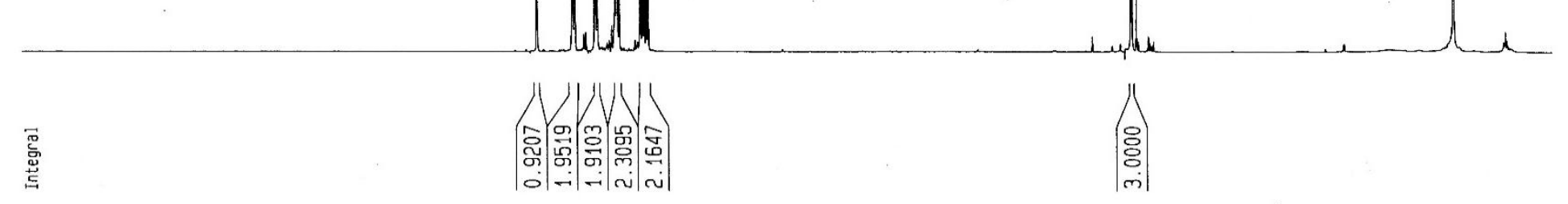



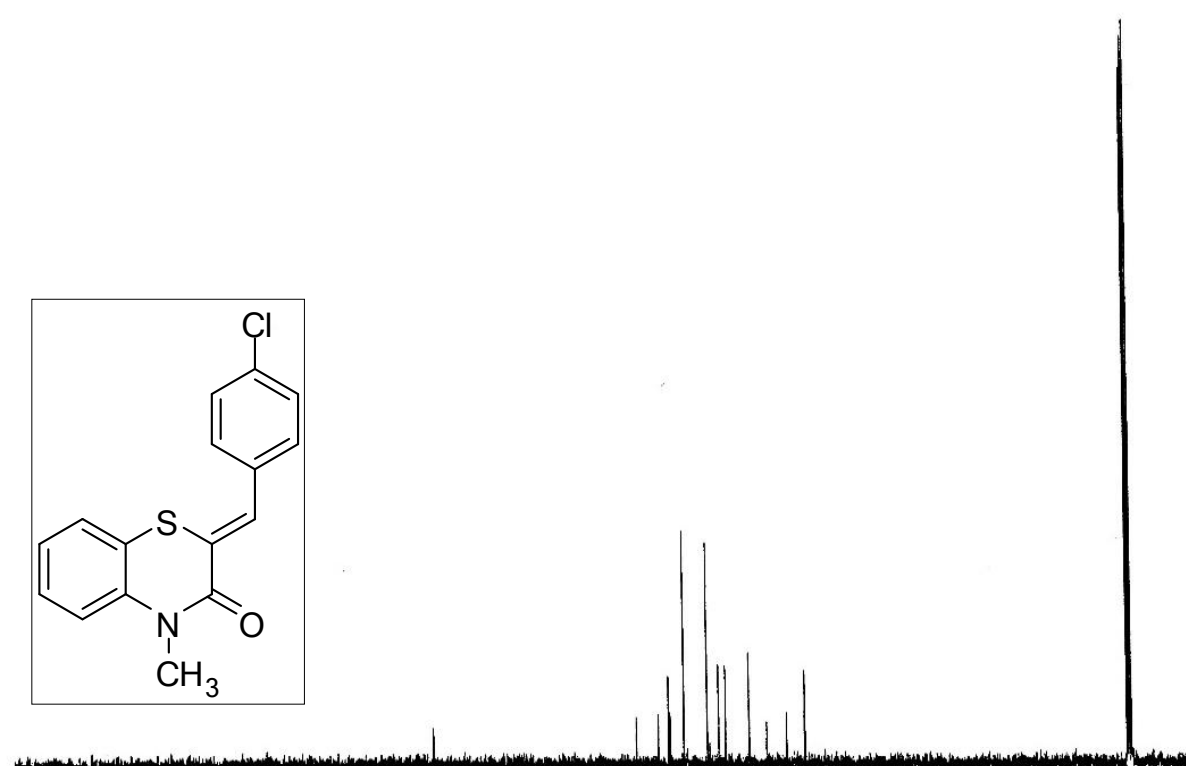

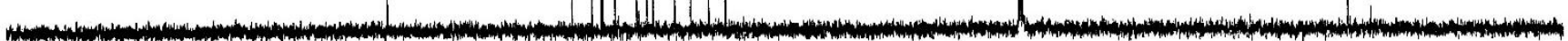

${ }^{13}$ CNMR of $3 f$ 